\title{
SELECTION OF B CHROMOSOMES IN SECALE CEREALE AND LOLIUM PERENNE
}

\author{
J. HUTCHINSON \\ Department of Agricultural Botany, University College of Wales, Aberystwyth
}

Received 1.iv.74

\section{Summary}

Secale cereale

A series of three experiments was carried out to see if varying sowing density had any differential effect upon the survival of plants with and without B chromosomes. In all experiments it was shown that as sowing density increased, and therefore the selection pressure increased, so the mean $B$ frequency decreased. This was accounted for by an increasing survival at high densities of plants without $\mathbf{B}$ chromosomes.

\section{Lolium perenne}

In contrast to the results in rye, increasing sowing density in Lolium perenne caused an increase in the mean B frequency. This was accounted for by a decrease in the number of plants without $B$ chromosomes and a corresponding increase in the frequency of plants with $2 \mathrm{~B}$ chromosomes.

From the results of these experiments in Secale and Lolium it is concluded that the change in B frequency within and between populations is an adaptive response to the different kinds, and degree of selection to which the populations are exposed. The results argue against the view that $\mathrm{B}$ chromosomes are " nuclear parasites" with, invariably, detrimental consequences.

\section{INTRODUCTION}

The frequency and distribution of $\mathbf{B}$ chromosomes in many natural populations have been shown to be correlated with environmental factors. These correlations, together with evidence showing that B's appear to affect many aspects of growth and development, have led to the suggestion that $\mathbf{B}$ chromosomes have an adaptive significance (see Rees and Hutchinson, 1973). An alternative hypothesis, however, is that B chromosomes are nuclear "parasites" (Óstergren, 1945; Rhoades and Dempsey, 1972), being maintained in populations by means of their non-Mendelian transmission in heredity, while themselves being genetically inert (Östergren, loc. cit.), or even deleterious in their effects (Rhoades and Dempsey, loc. cit.).

In view of this difference of opinion, it is clearly necessary to find out experimentally whether the "fitness" of individuals with and without B chromosomes varies with changing environmental conditions. Experiments with B-carrying populations of Secale cereale (Rees and Ayonoadu, 1973) and Lolium perenne (Williams, personal communication) demonstrated a shift in $B$ frequency in outdoor populations exposed to selection pressures of different kind and intensity. The populations were grown at two different sites, at different seasons and at different plant spacings. Unfortunately, with these experiments it was impossible to specify precisely the factors which influenced the B-frequency variation. Effects of soil and weather, for example, were confounded. The present experiments, also on Secale and Lolium, were 
therefore restricted to investigating the effects of variation in one factor, namely the population density.

\section{Materials and methods}

(i) Secale cereale

Plants from a Secale cereale population carrying B chromosomes, obtained from Japan in 1967 by R. N. Jones (for details see Kishikawa, 1965), were allowed to cross-pollinate so as to provide a large seed sample in 1968. These seeds were used throughout the series of experiments and are termed the "standard" rye population.

Seeds were sown $1 \mathrm{~cm}$ deep in John Innes No. 2 potting compost in "24-hole" plastic multipot trays (each pot having a diameter of $6 \cdot 5 \mathrm{~cm}$ ). The sowing densities used throughout the experiments were $5,10,25,50,75$, 100 and 150 seeds per pot. At each density, two replicates, each of 12 pots per replicate in Experiment I, and of 10 pots per replicate in Experiments II and III, were set up as follows:

Experiment I: Seeds were sown in September 1970 and the plants were allowed to grow to maturity in the multipot trays, which were placed in an unheated greenhouse at the Penglais site.

Experiments II and III: Seeds were sown in October 1971 and the multipot trays were placed respectively in the field at the Penglais site and in an unheated greenhouse at the Frongoch site.

At flowering time, the numbers of surviving plants per pot were recorded, and a random sample of heads was removed for fixation from each replicate density. The numbers of B chromosomes were then counted from meiotic preparations of the anthers of 20 plants (where possible), for each replicate density, in each experiment. The frequency and distribution of $\mathrm{B}$ chromosomes in the "standard" population was also established from mitotic counts and from meiotic preparations obtained from spaced plants.

\section{(ii) Lolium perenne}

The Lolium perenne material was derived from a population containing B chromosomes found in Northern Algeria in 1964 (see Cameron and Rees, 1967). Seeds from crosses between plants with 0, 1, 2 and $3 \mathrm{~B}$ chromosomes were thoroughly mixed and form the "standard "Lolium population.

Lolium seeds were sown in February 1972 in the same way as in the rye experiments. Two replicates, each of 10 pots per replicate, were sown at densities of $5,10,25,50,75$ and 100 seeds per pot. At flowering time, all heads were removed for fixation, the heads from each pot being kept separately. The numbers of B chromosomes were then counted in two heads chosen at random from each pot, giving a total of 20 heads scored per replicate per density. The B distribution of the "standard "population was established from the meiotic counts of single-spaced plants.

\section{Results}

\section{(i) Secale cereale}

The distributions of $\mathrm{B}$ chromosomes amongst the survivors at each sowing density in each of the three experiments are shown in fig. 1. An 
Experiment 1
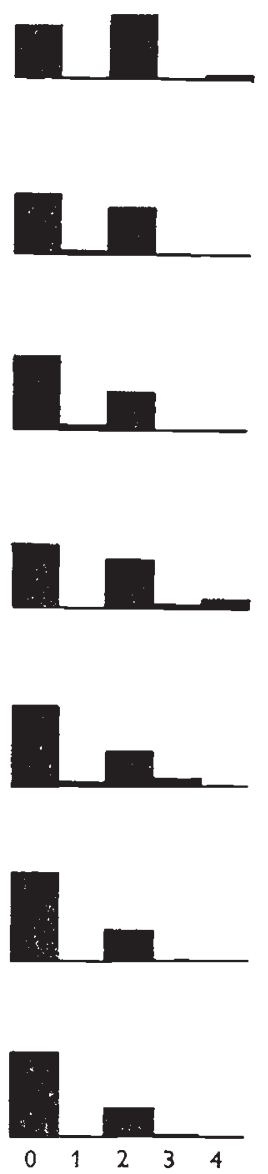

Experiment II
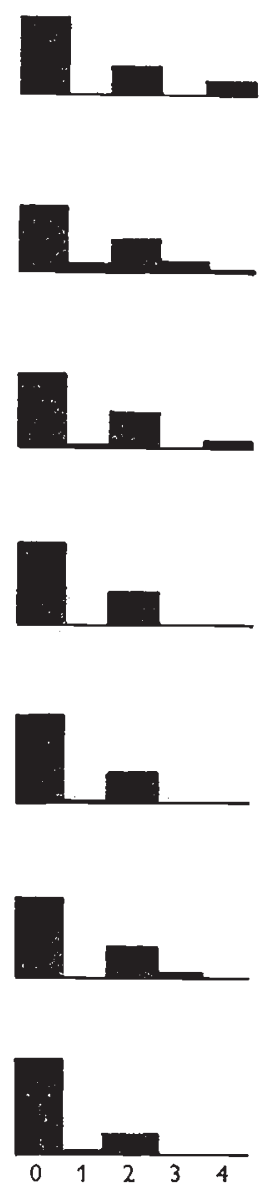

B Chromosomes

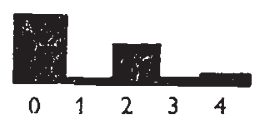

Experiment III

Density
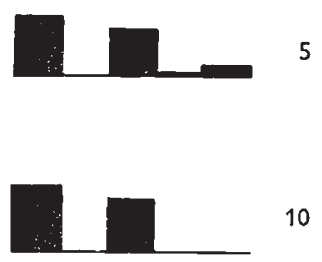

10

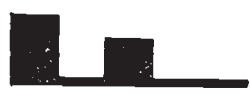

25

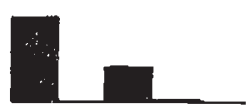

50

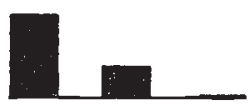

75

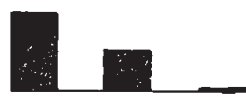

100

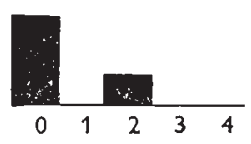

150

$$
\left.\begin{array}{l}
40 \\
20-\frac{\frac{n}{5}}{\frac{\pi}{2}} \\
0
\end{array}\right]
$$

Fig. 1.-The distribution of $\mathbf{B}$ chromosomes amongst the survivors of Secale cereale populations grown at seven different densities in three experiments. Data summed over replicates which were not significantly different.

overall contingency $\chi^{2}$ analysis was first of all carried out on the data as a whole, to find out if there were any significant differences in B chromosome distribution between the experiments or between plant densities. The data were pooled over the $\mathrm{IB}$ and $3 \mathrm{~B}$ classes since the numbers of plants in these classes were very small. The $\chi^{2}$ analysis is given in table 1 and shows that there is no significant difference between replicates or experiments, but that there is a highly significant variation in the distribution of $\mathrm{B}$ chromosomes 
amongst survivors of populations sown at different densities. The interaction between sites and densities is not significant.

It may therefore be concluded that there is a shift in B chromosome distribution which is consistent for the differing environments in which the experiments were carried out. Further analysis, using regression techniques, shows more precisely the nature of these changes in B chromosome distribution.

TABLE 1

Overall contingency $\chi^{2}$ analysis of Secale cereale $B$ chromosome distribution

\begin{tabular}{lrrr}
$\quad$ Item & d.f. & $\chi^{2}$ & \multicolumn{1}{c}{$\mathbf{P}$} \\
Densities & 18 & $41 \cdot 2909$ & $<0 \cdot 0005$ \\
Sites & 6 & 8.5222 & $0 \cdot 25-0 \cdot 1$ \\
Densities $\times$ Sites & 60 & 47.8357 & $0 \cdot 9$ \\
Replicates & 39 & $31 \cdot 6705$ & $0.9-0.75$
\end{tabular}

The mean B frequencies per plant in each of the replicate densities for the three experiments are given in table 2. The regression of mean $\mathbf{B}$ frequency on sowing density showed that in each experiment there was a significant decrease in the mean B frequency with increasing sowing density. A further joint regression analysis showed that the three regressions could be represented by one, highly significant, joint regression line $(P=0.001$, fig. 2). There were no significant heterogeneity items. It therefore appears that the effect of increasing sowing density is to cause an increase in the survival of plants without B chromosomes relative to plants with B's.

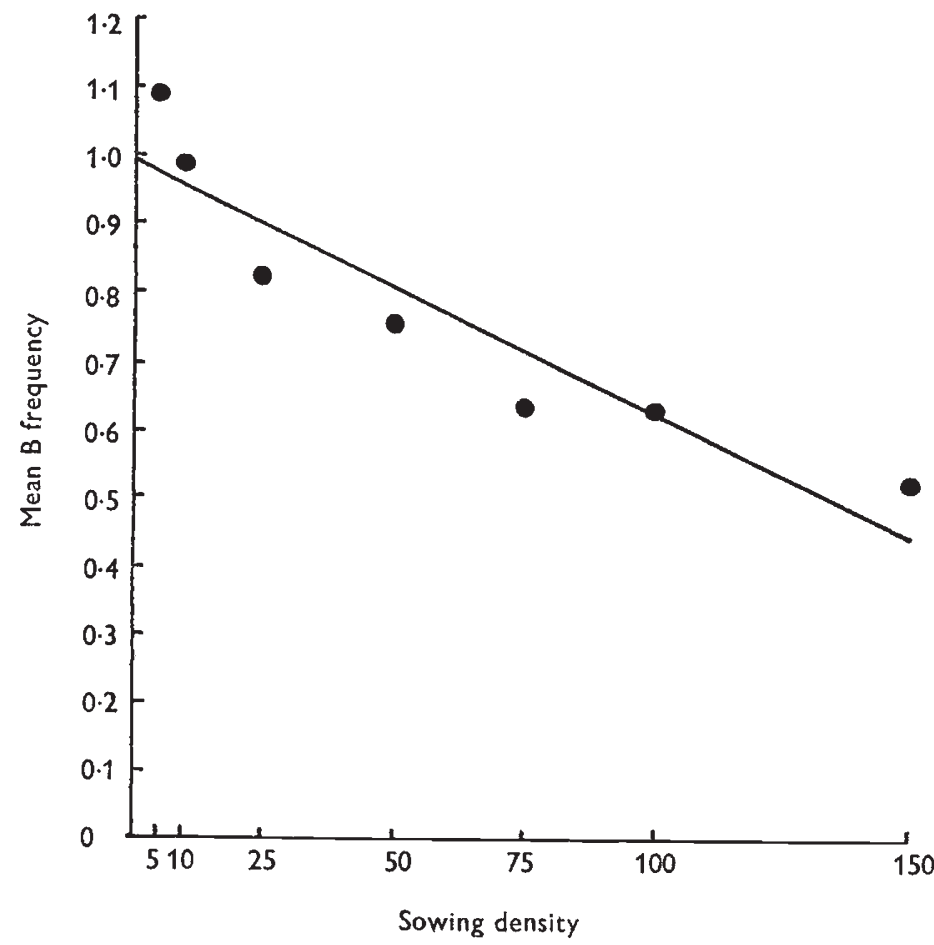

Frg. 2.-Decrease in mean $B$ frequency per plant with increasing sowing density shown in $S$. cereale populations. Data pooled over experiments and replicates. 
TABLE 2

Distribution and frequency of $B$ chromosomes among populations of Secale cereale grown at seven different sowing densities, in three experiments. The distribution of the "standard" population is also shown

Density

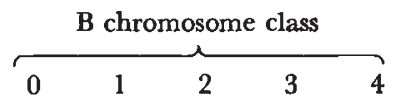

Total plants

Experiment I

$5 R_{1}$
$R_{2}$
10

25

50

75

100

150

Experiment II

$$
\begin{array}{r}
5 \mathbf{R}_{1} \\
\mathbf{R}_{2}
\end{array}
$$$$
10
$$

25

50

75

100

150

\section{Experiment III}

$$
\begin{gathered}
5 \mathbf{R}_{1} \\
\mathbf{R}_{2}
\end{gathered}
$$

10

25

50

75

100

150

"Standard" population

$\begin{array}{rrrrr}11 & - & 9 & - & - \\ 7 & - & 12 & - & 1 \\ 10 & 1 & 8 & - & 1 \\ 10 & - & 8 & - & 2 \\ 11 & 2 & 7 & - & - \\ 14 & - & 6 & - & - \\ 10 & - & 8 & 1 & 1 \\ 11 & - & 8 & - & 1 \\ 14 & - & 5 & 1 & - \\ 12 & 1 & 6 & 1 & - \\ 15 & - & 5 & - & - \\ 15 & - & 5 & - & - \\ 14 & - & 5 & 1 & - \\ 15 & - & 5 & - & -\end{array}$

20

20

20

20

20

20

20

20

20

20

20

20

20

20

Mean B

frequency

$$
\begin{aligned}
& 0.90 \\
& 1 \cdot 40 \\
& 1 \cdot 05 \\
& 1 \cdot 20 \\
& 0.80 \\
& 0 \cdot 60 \\
& 1 \cdot 15 \\
& 1 \cdot 00 \\
& 0 \cdot 65 \\
& 0 \cdot 80 \\
& 0.50 \\
& 0.50 \\
& 0.65 \\
& 0.50
\end{aligned}
$$

$0 \cdot 80$

$1 \cdot 14$

0.80

$1 \cdot 10$

0.61

$1 \cdot 00$

0.60

0.50

0.47

0.56

0.75

0.50

0.50

0.45 
As sowing density increases, it is expected that the proportion of plants surviving to maturity will decrease, and that mortality will be particularly high under the conditions of very high densities which apply in some of the populations. This was indeed shown in each of these experiments (fig. 3).

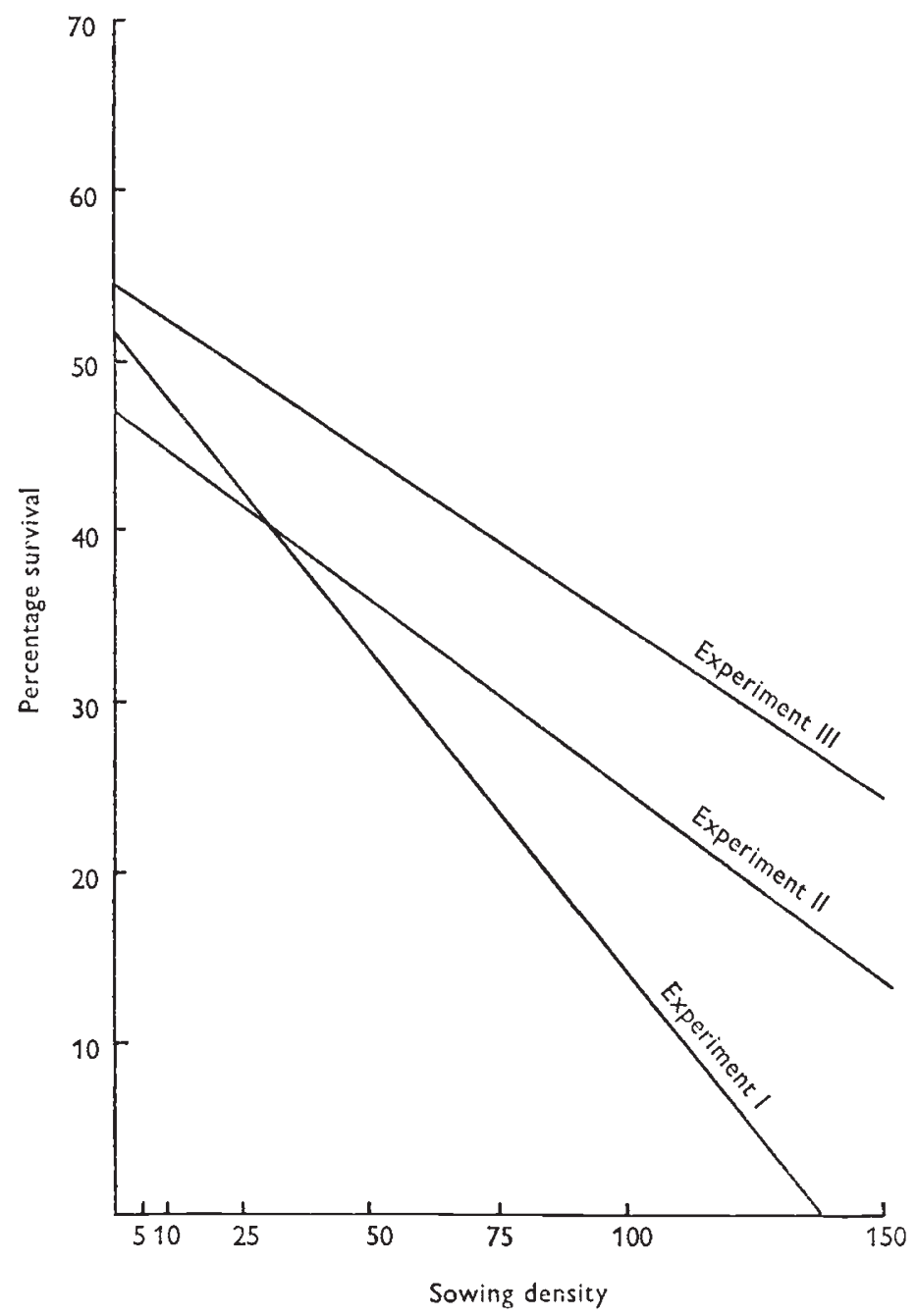

Frg. 3.-Regression of the percentage survival against sowing density for Secale cereale populations. Due to the design of the experiments where the number of seeds per pot varies in the different populations, and therefore the number of plants per pot varies, the precision with which the percentage survival was calculated also varied in these experiments, as shown by significant Bartlett tests of the variances. The mean percentage survival data (in angles) were therefore weighted by the reciprocals of the variances for the regression analyses.

However, as indicated by fig. 3 , an analysis of variance also showed that there were significant differences in the degree of mortality at comparable densities (table 3). Since the percentage survival or, conversely, the mortality is a reflection of the selection pressure at different density levels, it would 
appear that there are different degrees of selection pressure operating at comparable densities in the slightly differing environmental conditions provided by the three experiments. The change in mean B frequency in

TABLE 3

Analysis of variance of the percentage survival of Secale cereale plants to maturity. Data transformed to angles for analysis

\begin{tabular}{lrrrc}
\multicolumn{1}{c}{ Item } & d.f. & M.S. & V.R. & P \\
Densities & 6 & 633.5471 & $19 \cdot 77$ & $<0.001$ \\
Experiments & 2 & 294.5346 & $9 \cdot 19$ & 0.01 \\
Densities $\times$ Experiments & 12 & 32.0462 & 3.27 & 0.01 \\
Error & 21 & 9.8014 & &
\end{tabular}

direct relation to mortality was therefore examined. The regressions of mean B frequency on percentage survival for each experiment showed, as expected, significant positive relationships. A joint regression analysis (table 4) also showed that the joint regression item was highly significant. The heterogeneity items were not significant, and therefore the slopes of all the regressions were essentially the same. It is clear that a differential mortality, due mainly to differences in sowing density, is causally related to the variation in $\mathrm{B}$ frequency amongst the survivors.

TABLE 4

Joint regression analysis of $B$ frequency against percentage survival of Secale cereale

\begin{tabular}{lrcrc}
\multicolumn{1}{c}{ Item } & d.f. & M.S. & V.R. & P \\
Joint regression & 1 & 1.4693 & 37.97 & $<0.001$ \\
Heterogeneity of regressions & 2 & 0.0370 & 0.97 & n.s. \\
Heterogeneity of means & 2 & 0.0670 & 1.47 & n.s. \\
Error & 36 & 0.0387 & &
\end{tabular}

Since the same "standard" seed population was used throughout the experiments, i.e. in all three " environments", any deviation from the B chromosome distribution of this population may be presumed to result entirely from the density treatments. Comparisons between the "standard" and the populations at varying densities will also provide details about the change in $\mathrm{B}$ distribution. A $\chi^{2}$ analysis of the data is given in table 5 . This

TABLE 5

Comparison of the distribution of $B$ chromosomes at different densities with the distribution in the "standard" rye population. Data pooled over replicates and experiments

\begin{tabular}{ccc} 
Density & $\chi^{2}(3)$ & \multicolumn{1}{c}{$P$} \\
5 & $7 \cdot 3290$ & $0 \cdot 1-0 \cdot 05$ \\
10 & $2 \cdot 1158$ & $0 \cdot 75-0.5$ \\
25 & $4 \cdot 0035$ & $0 \cdot 25$ \\
50 & $9 \cdot 4600$ & $0 \cdot 025$ \\
75 & $12 \cdot 3597$ & $<0 \cdot 001$ \\
100 & $17 \cdot 0102$ & $<0 \cdot 001$ \\
150 & $21 \cdot 6613$ & $<0 \cdot 001$
\end{tabular}

shows that there is a marked deviation from the "standard" population at high densities. Significant $\chi^{2}$ were obtained at densities of 50,75, 100 and 150 seeds per pot. This effect is illustrated in fig. 4, showing the deviation of each population density from the "standard" population. It will be 
observed that the deviations at high densities are due to an excess of plants without $\mathrm{B}$ chromosomes, and a consequent decrease in the proportion of Bcarrying plants. The results in terms of density are therefore very much like those found by Rees and Ayonoadu (1973) in field experiments.

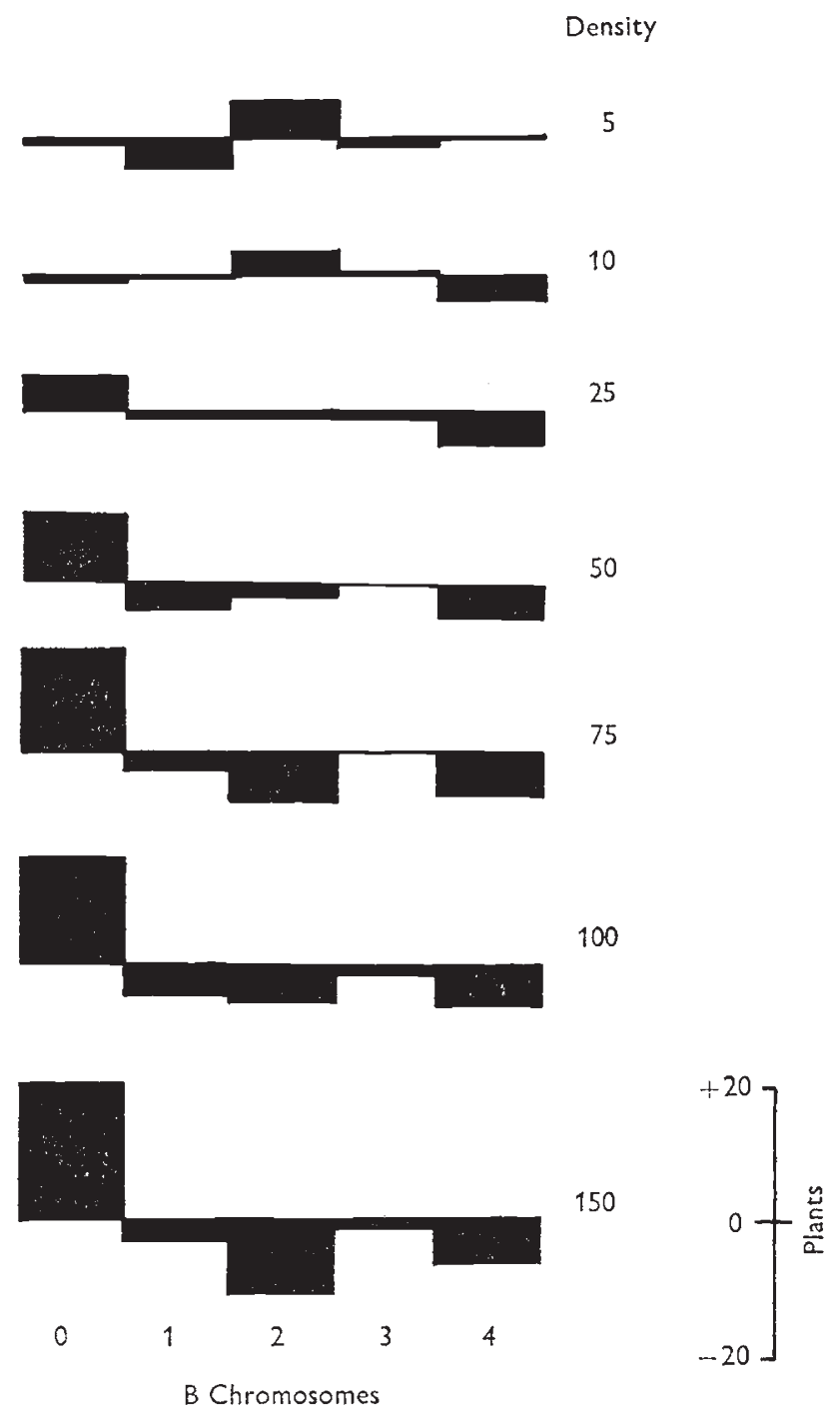

Fig. 4.-Deviation from the "standard" rye population of plants grown at varying densities (summed over experiments and replicates).

The $\chi^{2}$ value for the deviation of populations at a density of 5 seeds per pot, as compared with the "standard" has a probability of just over 0.05 . It is not quite significant, but does nevertheless reflect an undoubted tendency for a shift from the "standard" distribution. At densities of 10 and 25 seeds per pot there is no significant deviation from the "standard" population. 
Fig. 4 confirms that in general the frequency of $\mathrm{OB}$ plants at low densities is very similar to that in the "standard" population. There is, however, at a density of 5 seeds per pot, a strong indication of an excess over expectation of B-carrying plants, especially of those with 2B's.

These results therefore show that the "fitness" of Secale cereale plants with and without B chromosomes varies with changing environmental conditions. Although it appears that B-carrying plants are selected against under the adverse conditions of high density, there is some slight indication from the low densities, that there may be some conditions in which the selection would favour B chromosomes. This evidence is, however, not entirely conclusive.

Density

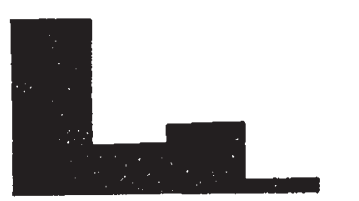

5

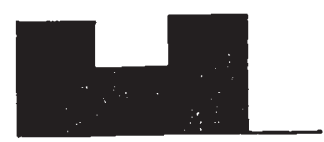

10

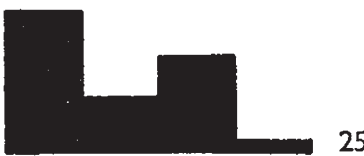

25
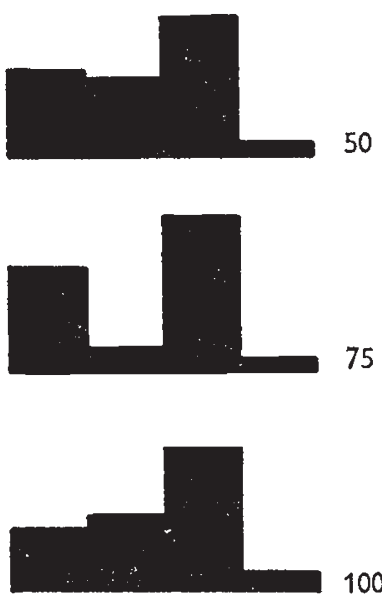

$100 \quad \begin{gathered}20 \\ 10 \\ \frac{5}{\frac{E}{2}}\end{gathered}$

$\begin{array}{llll}0 & 1 & 2 & 3\end{array}$

B Chromosomes

FIG. 5.-Distribution of B chromosomes in Lolium perenne populations grown at six different densities. Summed over replicates. 
More convincing evidence for an increased fitness of individuals carrying B's comes from the results of the Lolium experiment.

\section{(ii) Lolium perenne}

The distribution of B chromosomes amongst the plants flowering in each of the six densities are shown in fig. 5. During the screening, one trisomic plant, one tetrasomic plant, and one plant with multiploid sporocyte formation were encountered. These plants were excluded from the data. The diploid numbers of $\mathbf{B}$ chromosomes in three mixaploid plants were, however, recorded and included in the data. An overall contingency $\chi^{2}$ analysis of the data (table 6) shows that there is no significant variation between replicates and that the probability of significant variation between densities is $0 \cdot 1-0 \cdot 05$, nearly, but not quite significant.

TABLE 6

Overall contingency $\chi^{2}$ analysis of Lolium perenne $B$ chromosome distributions

\begin{tabular}{lccc}
\multicolumn{1}{c}{ Item } & d.f. & $\chi^{2}$ & $\mathrm{P}$ \\
Densities & 15 & $23 \cdot 1596$ & $0 \cdot 1-0.05$ \\
Replicates & 18 & $14 \cdot 4251$ & $0 \cdot 75-0.5$ \\
Total & 33 & 37.5847 &
\end{tabular}

While the straightforward $\chi^{2}$ analysis shows no significant difference in B chromosome distribution, there is nevertheless an undoubted trend in B frequency, namely an increase with increasing density (fig. 5). This is especially marked with respect to the $0 \mathrm{~B}$ and $2 \mathrm{~B}$ classes which decrease and increase respectively as sowing density increases. A more sensitive test of the variation, by means of regression, is described below:

The mean B frequency per plant for each replicate population at each density is given in table 7 . The regression analysis shows a significant

TABLE 7

Distribution and frequency of $B$ chromosomes among populations of $\mathrm{L}$. perenne grown at different densities. The $B$ distribution of the "standard" population is also shown

\begin{tabular}{|c|c|c|c|c|c|c|}
\hline \multirow[b]{2}{*}{ Density } & \multicolumn{4}{|c|}{ B chromosome class } & \multirow[b]{2}{*}{$\begin{array}{l}\text { Total } \\
\text { plants }\end{array}$} & \multirow[b]{2}{*}{$\begin{array}{r}\text { Mean B } \\
\text { frequency }\end{array}$} \\
\hline & 0 & 1 & 2 & 3 & & \\
\hline $\begin{array}{r}5 \mathrm{R}_{1} \\
\mathrm{R}_{2}\end{array}$ & $\begin{array}{l}14 \\
10\end{array}$ & $\begin{array}{l}3 \\
3\end{array}$ & $\begin{array}{l}3 \\
6\end{array}$ & - & $\begin{array}{l}20 \\
20\end{array}$ & $\begin{array}{l}0 \cdot 4500 \\
0.9000\end{array}$ \\
\hline 10 & $\begin{array}{l}8 \\
7\end{array}$ & $\begin{array}{l}5 \\
4\end{array}$ & $\begin{array}{l}7 \\
9\end{array}$ & - & $\begin{array}{l}20 \\
20\end{array}$ & $\begin{array}{l}0 \cdot 9500 \\
1 \cdot 1000\end{array}$ \\
\hline 25 & $\begin{array}{r}9 \\
10\end{array}$ & $\begin{array}{l}5 \\
2\end{array}$ & $\begin{array}{l}5 \\
8\end{array}$ & 1 & $\begin{array}{l}20 \\
20\end{array}$ & $\begin{array}{l}0 \cdot 9000 \\
0 \cdot 9000\end{array}$ \\
\hline 50 & $\begin{array}{l}5 \\
6\end{array}$ & $\begin{array}{l}6 \\
4\end{array}$ & $\begin{array}{l}9 \\
9\end{array}$ & - & $\begin{array}{l}20 \\
20\end{array}$ & $\begin{array}{l}1 \cdot 2000 \\
1 \cdot 2500\end{array}$ \\
\hline 75 & $\begin{array}{r}4 \\
10\end{array}$ & $\begin{array}{l}1 \\
2\end{array}$ & $\begin{array}{r}12 \\
8\end{array}$ & 1 & $\begin{array}{l}18 \\
20\end{array}$ & $\begin{array}{l}1.5555 \\
0 \cdot 9000\end{array}$ \\
\hline 100 & $\begin{array}{l}5 \\
2\end{array}$ & $\begin{array}{l}3 \\
6\end{array}$ & $\begin{array}{r}6 \\
11\end{array}$ & $\begin{array}{l}1 \\
1\end{array}$ & $\begin{array}{l}15 \\
20\end{array}$ & $\begin{array}{l}1.2000 \\
1.5500\end{array}$ \\
\hline $\begin{array}{l}\text { "Standard } \\
\text { population }\end{array}$ & 22 & 12 & 15 & 1 & 50 & 0.9000 \\
\hline
\end{tabular}


increase in mean $B$ frequency with increasing sowing density $(P=0.05$, fig. 6). This contrasts sharply with the situation in rye, where, it will be recalled, the mean $B$ frequency decreases with increasing sowing density.

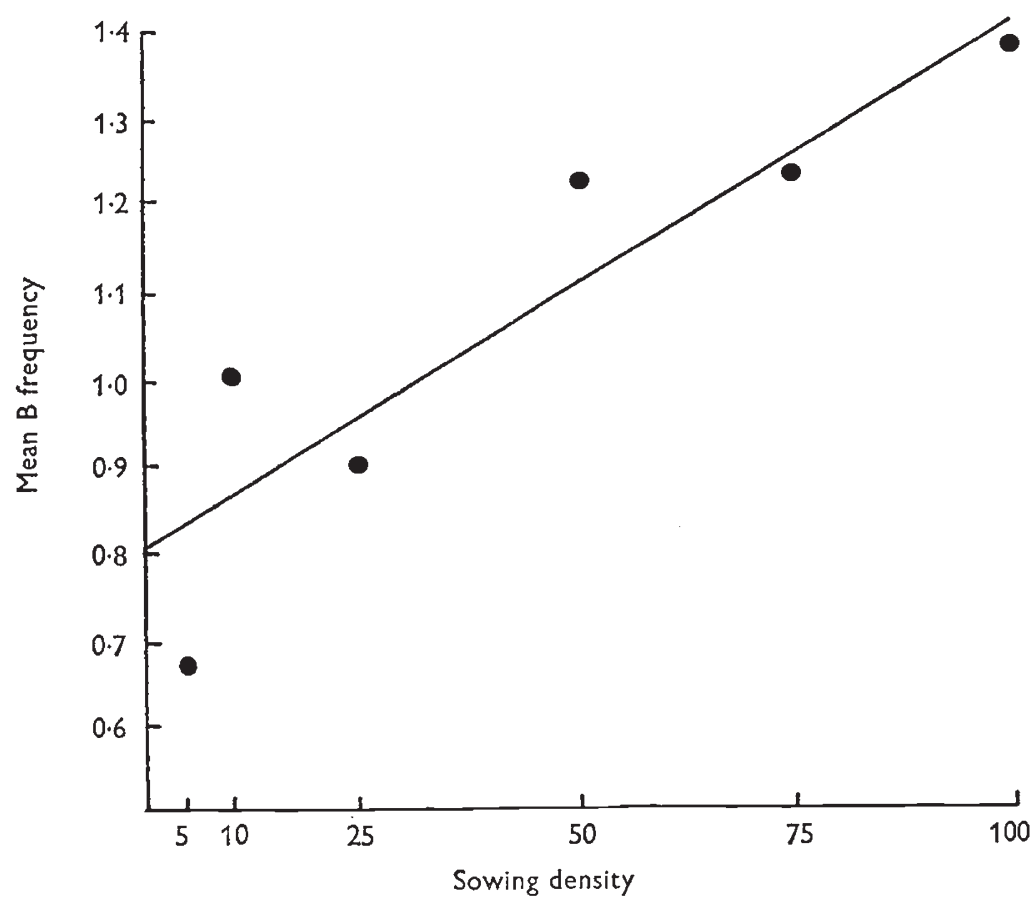

FIG. 6.-Increase in mean B frequency with increasing density in $L$. perenne populations.

In the Lolium experiment, unlike the rye experiments where at flowering time each plant is represented by just one tiller, each $L$. perenne plant may have many vegetative tillers. These are often intertwined with each other and it is not possible to determine from which plant any flowering tiller originated. Although the indications are that under high sowing densities the numbers of flowering tillers per plant are reduced, and that each flowering tiller probably represents one plant, sampling was limited to two heads per pot within each replicate to minimise the possible bias of sampling each plant more than once. In Lolium, therefore, the indications are for a superior capacity for survival of B-carrying plants under the conditions of increasing stress imposed by high density.

TABLE 8

$\chi^{2}$ comparison of the distribution of $B$ chromosomes at different densities with the distribution in the "standard" population of Lolium perenne

\begin{tabular}{ccl} 
Density & $\chi^{2}(3)$ & \multicolumn{1}{c}{$\mathbf{P}$} \\
5 & $4 \cdot 4772$ & $0.3-0.2$ \\
10 & 2.5548 & 0.5 \\
25 & 0.9487 & $0.9-0.8$ \\
50 & 5.5416 & $0.2-0.1$ \\
75 & 11.1126 & $0.02-0.01$ \\
100 & 11.0626 & $0.02-0.01$
\end{tabular}


These indications are confirmed by means of a comparison, by means of $\chi^{2}$ analysis, of the $B$ distributions of populations grown at different densities with the B distribution of the "standard" population shown in table 7 . The analysis of the data pooled over replicates is presented in table 8 . This shows that there are significant deviations from the "standard" Lolium population at the high densities of 75 and 100 seeds per pot only. Fig. 7 illustrates that the deviations are in the direction of an increased frequency of plants with $2 \mathrm{~B}$ chromosomes and of a corresponding decrease of $\mathrm{OB}$ plants. These results confirm those found by Williams (1970) under field conditions.

Density

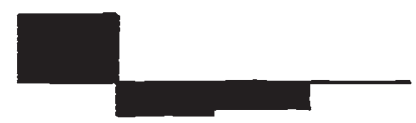

5

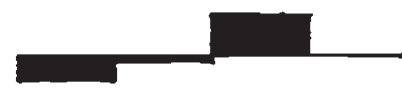

10

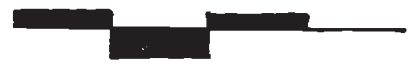

25
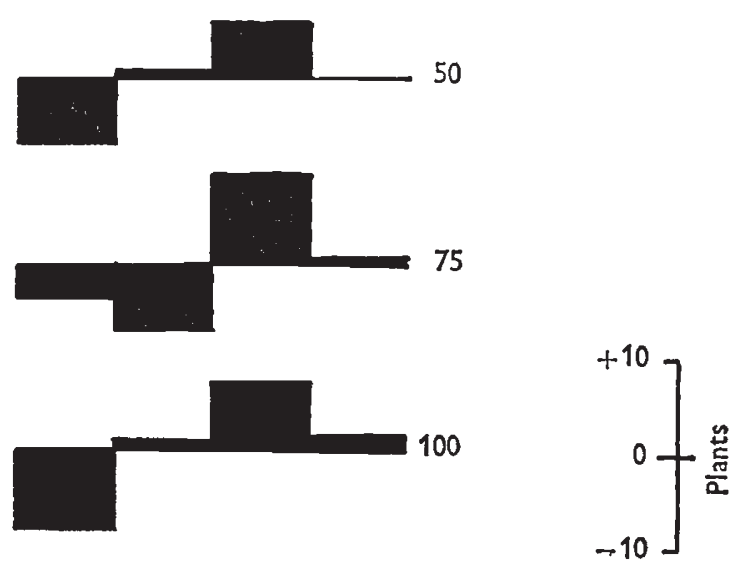

$\begin{array}{llll}0 & 1 & 2 & 3\end{array}$

B Chromosomes

Fig. 7.-Deviation from the "standard" Lolium population of plants grown at varying densities (summed over replicates).

\section{Discussion}

The present experiments have shown quite clearly that the B chromosome frequency among populations may be altered quite easily by changes in 
population density. Variation in population density is an important factor in the regulation of variability in populations due to the variation in fitness of genotypes in competition with one another. As population density increases, the competition for resources obviously becomes more severe, and so only the fittest members of the population survive. This " populationdependent" selection pressure may be resolved into two, possibly interacting, components - frequency-dependent and density-dependent selection (Turner and Williamson, 1968). When frequency-dependent selection is operating, the fitness of any particular genotype is dependent on the frequency of that genotype relative to other genotypes in the population. With densitydependent selection, however, it is the density of the population as a whole which is important, irrespective of the relative frequencies of the different genotypes. In the present experiments, the same "standard" seed populations were used throughout the experiments, and so the relative B chromosome frequencies have been assumed to be constant. The changes in B frequency resulting from increasing sowing density must therefore be attributed to increasing density-dependent selection pressure.

In the Secale populations, as the sowing density increased, so the frequency of $\mathrm{OB}$ plants among the survivors increased. This implies that in rye, the fitness of $\mathrm{OB}$ genotypes is greater than that of genotypes with $\mathrm{B}$ chromosomes, under the adverse conditions of high density. There is, in addition, a slight indication that at low sowing densities there may possibly be a selective advantage of the rye plants with B chromosomes (see fig. 4). The deviation of the low-density populations from the "standard" population was however not quite significant, and so this possibility is not proven, although it must be pointed out that when the experiments were analysed separately, significant deviations from the expected "standard" population were obtained at a density of 5 seeds per pot in Experiment I $\left(\chi^{2}{ }_{(3)}=7 \cdot 9445\right.$, $\mathrm{P}=0.05)$ and at a density of 10 seeds per pot in Experiment II $\left(\chi^{2}{ }_{3}\right)$ $=8 \cdot 0987, \mathrm{P}=0 \cdot 05-0 \cdot 025)$. This point obviously requires further experimentation since it is important to find out whether there are environmental conditions in which rye $B$ chromosomes may have a selective advantage as well as those in which they have a selective disadvantage. In the Lolium perenne populations, on the other hand, the plants with $2 \mathrm{~B}$ chromosomes displayed superior fitness in comparison to plants without $\mathrm{B}$ chromosomes.

These experiments therefore show that, since the fitness of the individuals carrying different numbers of B chromosomes varies with population density, $\mathrm{B}$ chromosomes have an adaptive signficance. The adaptive value of B's is also highly specific and may be advantageous or disadvantageous with regard to population density, depending upon the species and possibly the particular population, under consideration. It is especially important to stress the increase in B frequency with increasing density as in Lolium. This confirms not only an adaptive shift but also the superior fitness of individuals with B chromosomes under these particular conditions of growth. This would appear to rule out of court completely the concept of B's as intranuclear "parasites".

Acknowledgments.-I should like to thank Professor $\mathbf{H}$. Rees for his advice and criticism throughout this work and also for reading the manuscript. 


\section{References}

GAMERON, F. M., AND REES, H. 1967. The influence of B chromosomes on meiosis in Lolium. Heredity, 22, 446-450.

KISHIKAWA, H. 1965. Cytogenetic studies of B chromosomes in rye, Secale cereale L., in Japan. Agr. Bull. Saga Univ., 1-81.

ostergren, G. 1945. Parasitic nature of extra fragment chromosomes. Bot. Not., Lund., 2, 157-163.

ReES, H., AND AyonoAdu, U. 1973. B chromosome selection in rye. Theoret. Appl. Genet., 43, $162-166$.

REES, H., AND HUTchinson, J. 1973. Nuclear DNA variation due to B chromosomes. Cold Spr. Harb. Symp. Quant. Biol., 38 (in press).

RHOADES, M. M., AND DEMPSEY, E. 1972. On the mechanism of chromatin loss induced by the B chromosomes of maize. Genetics, 71, 73-96.

TURNer, J. R. G., AND Williamson, M. M. 1968. Population size, natural selection and the genetic load. Nature, Lond., 218, 700.

Williams, P. 1970. Genetical effects of B chromosomes in Lolium. Ph.D thesis, University of Wales. 